\title{
Production and Testing of Biopesticide for Control of Postharvest Mold Infections on Fresh Fruits of Apple and Pear
}

\author{
Yacoub A. Batta \\ Laboratory of Plant Protection, Department of Plant Production \& Protection, Faculty of Agriculture \& \\ Veterinary Medicine, An-Najah National University, Nablus, West Bank, Palestine \\ Email: yabatta@najah.edu
}

Received 8 October 2015; accepted 13 November 2015; published 16 November 2015

Copyright (C) 2015 by author and Scientific Research Publishing Inc.

This work is licensed under the Creative Commons Attribution International License (CC BY). http://creativecommons.org/licenses/by/4.0/

c) (i) Open Access

\section{Abstract}

The present research aimed at producing a biopesticide with proper formulation of invert emulsion (water-in-oil type) and effective strain of Trichoderma harzianum then, testing it against pathogens of postharvest mold infections (Botrytis cinerea \& Penicillium expansum) on fresh fruits of apple and pear. The proper formulation of invert emulsion (IE\#3) used for biopesticide production has the following ingredients $(100 \% \mathrm{w} / \mathrm{w})$ : soybean oil $(28.50 \%)$, coconut oil $(19.50 \%)$, oilsoluble emulsifier: Tween $20(2.0 \%)$, glycerine $(4.25 \%)$, water-soluble emulsifier: dehymuls $k$ $(0.75 \%)$, sterile distilled water $(22.5 \%)$ and conidial suspension of the effective strain of $T$. harzianum "TrichoPAL1" in water $\left(22.5 \%\right.$, concentration $1 \times 10^{7}$ conidia $\left./ \mathrm{ml}\right)$. Testing efficacy of the produced biopesticide has indicated a significant reduction in the disease lesion diameter of mold infections on wounded apple and pear fruits stored at $20^{\circ} \mathrm{C} \pm 1^{\circ} \mathrm{C}$ compared to the untreated fruits or control (reduction from up to 38.75 to about $7.50 \mathrm{~mm}$, respectively, according to the type of mold infections and fruit type). Also, the treatment with the produced biopesticide has resulted in a long protection period from mold infections on wounded and un-wounded fresh fruits of apple and pear stored under controlled and semi-commercial conditions (up to 2.5 months according to the type of mold infections and fruit type). In conclusion, the overall results have demonstrated the effectiveness of produced biopesticide on stored fruits under controlled and semi-commercial conditions therefore, it is recommended to test this effectiveness on marketed fruits stored under variable conditions before applying it at a large scale.

\section{Keywords}

Apple Fruit, Pear Fruit, Trichoderma harzianum, Botrytis cinerea, Penicillium expansum, Biopesticides, Postharvest Mold Infections 


\section{Introduction}

The control of postharvest mold infections on fresh fruits is usually done by the conventional use of synthetic fungicides [1] [2]. Alternative approaches to chemical use are highly appreciated due to the increasing importance of integrated management strategies relying on biocontrol possibly combined with selective application of fungicides [3] [4]. The above strategies must achieve two demands: effectiveness and environmental safety. Also, integrated control could be a convenient strategy for newer attempts in the control of postharvest mold infections [5] [6].

Regarding the group of interesting biocontrol agents that can be involved in the integrated management strategies, the antagonistic fungi are considered the most promising agents because they are currently being developed as a novel approach for the control of many plant diseases [7]. However, these fungi suffer from the following disadvantages: i) their initial or acute biocontrol potential is much slower in comparison with chemical fungicides; ii) they need high humidity for conidial germination and subsequent development and sporulation; iii) they are susceptible to UV irradiation; and iv) some targeted plant diseases may develop defence mechanisms against the fungal attack. Some of these constraints could be overcome by developing, for example, formulations which improve the stability of these fungi, UV resistance, distribution on the surface of disease host-plant, and contact to the targets or can synergistically enhance efficacy by improving the virulence of these fungi [8] [9].

The use of antagonistic fungi as biocontrol agents of plant diseases, for example, postharvest mold infections, has been previously reported by some investigators [10]-[13], but without attempting to formulate these biocontrol agents during their application. Therefore, formulation of these fungi is crucial for increasing their efficacy during application against targeted plant diseases. Invert Emulsions (water-in-oil type) are one of the promising formulations that can be used for antagonistic fungi because these emulsions contain the necessary water for germination of fungal conidia and their development during or after application. The water introduced into emulsions is usually homogenized with oil at a high speed (20,000 rpm for 1.5 minutes using homogeniser), thus the water droplets in the final emulsions are completely surrounded by the oil droplets (water-in-oil emulsion). Therefore, oil droplets prevent the water droplets from quick evaporation. Under hot dry conditions, water used for preparation of the conidial suspension of these fungi will evaporate and dry up quickly but if this water is incorporated into invert emulsions as described above, it will evaporate very slowly following application due to the above reason [14].

Recently, research studies conducted in our laboratory under controlled environmental conditions have shown that certain strains of Trichoderma harzianum applied in invert emulsion are proved to be effective against fungal plant pathogens infecting the fresh produce of various crops including fruits postharvest [15]-[17]. Therefore, in the present research, biopesticides based on using new combinations (formulations) of invert emulsions with effective strain(s) of the antagonistic fungus- $T$. harzianum will be produced then tested against postharvest mold infections on apple and pear fruits stored under variable environmental conditions and in semi-commercial conditions. Therefore, the main objective of the present research was to produce an effective biopesticide against postharvest mold infections on apples and pears and then test its effectiveness. To arrive this objective, the following aims should be fulfilled: i) screening for selection of the most effective strain of Trichoderma harzianum against postharvest mold infections; ii) formulation of the selected strain of $T$. harzianum using new combinations of invert emulsion formulation; iii) testing the efficacy of the formulated strain of T. harzianum in invert emulsions against mold infections especially those caused by Botrytis cinerea and Penicillium expansum on apple and pear fruits stored in incubator or under semi-commercial conditions.

\section{Materials and Methods}

\subsection{Isolation of Pathogens Causing Mold Infections on Fresh Fruits of Apple and Pear}

The following postharvest mold infections of fruits were studied in the present research: Gray mold caused by Botrytis cinerea and Blue mold caused by Penicillium expansum. Local strains of B. cinerea (designated BCPAL) and P. expansum (designated PEPAL) were isolated on Potato Dextrose Agar medium (PDA) amended with Chloramphenicol antibiotic ( $250 \mathrm{mg} / \mathrm{L} \mathrm{W} / \mathrm{V}$, added to the medium after autoclaving). The two strains were isolated from naturally infected fruits of apple (source: a local wholesale market). Pure cultures of these isolated strains were used after sub-culturing of them on the same culture medium (PDA). These cultures were kept in a cold room at $4^{\circ} \mathrm{C} \pm 1^{\circ} \mathrm{C}$ for being used during bioassays' conduction. 


\subsection{Isolation of Strains of the Antagonistic Fungus: T, harzianum}

Local strains of $T$. harzianum were used in the present bioassays since this fungus has an antagonistic effect to many causal agents of fungal plant diseases including postharvest mold fungi of fresh fruits. Four local strains of T. harzianum were isolated from dead tomato roots previously infected with root rot fungi and then buried in the soil cultivated with various crops in Tulkarm district, Palestine. The isolated strains were designated "TrichoPAL1", "TrichoPAL2", "TrichoPAL3" and "TrichoPAL4". They were first isolated on Potato Dextrose Agar medium (PDA) amended with Chloramphenicol antibiotic ( $250 \mathrm{mg} / \mathrm{L} \mathrm{W} / \mathrm{V}$, added to the medium after autoclaving). Identification of these strains as isolates of $T$. harzianum was made according to the typical morphological characteristics of this fungus described by Grondona et al. 1997. After sub-culturing of these strains on oatmeal agar medium (OMA), pure cultures of these strains were kept in a cold room $\left(4^{\circ} \mathrm{C} \pm 1^{\circ} \mathrm{C}\right)$ for being used during bioassays' conduction.

\subsection{Screening Test for the Efficacy of Isolated T. harzianum Strains}

Efficacy of the isolated strains of $T$. harzianum was tested against postharvest mold infections for screening the most effective strain. For this purpose, healthy apple and pear fruits were infected with $B$. cinerea (strain BCPAL) and P. expansum (strain PEPAL) then treated with the conidial suspension of T. harzianum isolates at a concentration of $1 \times 10^{7}$ conidia/ml each. Comparison of the efficacy of these strains was done according to the suppression level of the disease lesion diameter resulted from B. cinerea and P. expansum infection on fruits used in bioassays. The infection with $B$. cinerea and $P$. expansum on apple and pear fruits and then treating them with the antagonistic fungus ( $T$. harzianum) was done by depositing $25 \mu \mathrm{l}$-droplet of conidial suspension of $B$. cinerea or $P$. expansum (concentration $1 \times 10^{6}$ conidia $/ \mathrm{ml}$ ) per fruit after inducing a small superficial wound on each fruit surface. A micropipette (100 $\mu \mathrm{l}$ capacity) is used for depositing of each droplet on each fruit. The control treatment is consisting of superficially wounded fruits treated with $25 \mu$ l-droplet of sterile distilled water. Inoculated and control fruits were then treated with conidial suspension of the following T. harzianum strains: "TrichoPAL1", "TrichoPAL2", "TrichoPAL3" and "TrichoPAL4". This treatment was done by depositing 25 $\mu \mathrm{l}$-droplet of conidial suspension (concentration $1 \times 10^{7}$ conidia/ml each) of each strain per fruit at the same site of disease inoculation using a $100 \mu \mathrm{l}$-micropipette. Four fruits representing 4 replicates per inoculated fruit type per pathogen per $T$. harzianum strain or control treatment were used. Each fruit was kept in a closed plastic pot of $9 \mathrm{~cm}$ diameter and $15 \mathrm{~cm}$ depth. A completely randomized design was used. The disease lesion diameter obtained 7 days after the treatment with the antagonistic fungus and incubation at $20^{\circ} \mathrm{C} \pm 1{ }^{\circ} \mathrm{C}$ was measured on each fruit then the mean lesion diameter of each disease on each fruit type per disease per $T$. harzianum strain was calculated. Finally, the Average mean of disease lesion diameter per strain of $T$. harzianum was calculated and used for comparison of the efficacy of tested strains to select the most effective one.

\subsection{Preparation of Invert Emulsion Formulations and Selection of the Most Proper}

New combinations of invert emulsion formulations (water-in-oil type) were prepared in this research. Each combination was mainly consisted of two phases: i) aqueous or water phase comprising of sterile distilled water, glycerine and water-soluble emulsifier, and ii) oil phase comprising of plant-origin oil(s) and oil-soluble emulsifier. The proportion of each phase in the final invert emulsion was $50 \%(\mathrm{w} / \mathrm{w})$ and the percentage of ingredients in each phase was changed during preparation so that the resulting combination was accepted as a suitable formulation if it had a high stability and low viscosity. Mixing of the two phases during preparation of the emulsion was done at a high speed (20,000 rpm for 1.5 minutes using a homogenizer). This is done to ensure the homogeneity of the emulsion. Five combinations were prepared using the above technique in order to select the most proper one characterized by the highest stability and lowest viscosity. The stability of the prepared emulsion was judged by the non-separation of the two phases composing the emulsion along the time following preparation. The viscosity of the prepared emulsion was measured by a viscometer. The emulsion is considered "not viscous" if its viscosity $<25$ cps (centipoises), "relatively viscous" if its viscosity $25-35$ cps and viscous if its viscosity $>35$ cps.

\subsection{Introduction of the Most Effective Strain of T. harzianum into the Selected Formulation of Invert Emulsion}

The most effective strain of $T$. harzianum obtained by screening in the above section was introduced into the se- 
lected formulation of invert emulsion characterized by the highest stability and lowest viscosity. Introduction was done, at first, into the aqueous or water phase which finally become consisted of sterile distilled water, conidial suspension of the effective strain of $T$. harzianum, glycerine and water-soluble emulsifier. The ingredients of oil phase did not change and remained as indicated above. The ratio of these two phases in the final invert emulsion was the same as indicated above. Conidial suspension of the most effective strain of $T$. harzianum in the formulation was $1 \times 10^{7}$ conidia/ml. Mixing of the two phases after introduction of the conidial suspension of the antagonistic fungus was done as indicated in the previous section to ensure the homogeneity of the emulsion.

\subsection{Testing Efficacy of Formulated Strain of T. harzianum against Postharvest Mold Infections on Fruits}

The efficacy test was practiced against mold infections on wounded and unwounded fruits of apple and pear stored at $20^{\circ} \mathrm{C} \pm 1^{\circ} \mathrm{C}$ in the incubator or at $20^{\circ} \mathrm{C} \pm 5^{\circ} \mathrm{C}$ under semi-commercial conditions as follows.

\subsubsection{Efficacy on Wounded Fruits of Apple and Pear Stored in Incubator at $20^{\circ} \mathrm{C} \pm 1^{\circ} \mathrm{C}$}

To test efficacy of the most effective strain of $T$. harzianum formulated in invert emulsion against pathogens of postharvest mold infections, healthy fruits of apple and pear were, first, infected with B. cinerea and P. expansum then, treated with the formulated $T$. harzianum according to the protocol indicated in the previous section. Comparison of the efficacy after the treatment was done according to the suppression level of the disease lesion diameter resulted from $B$. cinerea or $P$. expansum infection on treated fruits. The technique of inoculation with the mold pathogens on apple and pear fruits and then treatment with the formulated $T$. harzianum was done by depositing $25 \mu \mathrm{l}$-droplet of conidial suspension of each one of mold pathogens (concentration $1 \times 10^{6}$ conidia/ml) per fruit after inducing a small circular superficial wound ( $2 \mathrm{~mm}$ diameter) on each fruit surface. A micropipette (100 $\mu$ l capacity) was used for depositing the droplet on the wounded fruit. The control treatment is consisting of superficially wounded fruits treated with $25 \mu \mathrm{l}$-droplet of sterile distilled water. Inoculated and control fruits were then treated with $25 \mu \mathrm{l}$-droplet of formulated strain of $T$. harzianum (concentration $1 \times 10^{7} \mathrm{conidia} / \mathrm{ml}$ each) deposited at the same site of disease inoculation. In each bioassay, four types of treatments were used per pathogen per fruit type. The treatments were: formulated T. harzianum in invert emulsion, unformulated T. harzianum, blank formulation of invert emulsion and control (untreated with T. harzianum). Four fruits representing 4 replicates per treatment type were used. After that, each treated fruit was placed in a closed plastic pot $(9 \mathrm{~cm}$ diameter and $15 \mathrm{~cm}$ depth) then stored in an incubator at $20^{\circ} \mathrm{C} \pm 1{ }^{\circ} \mathrm{C}$. A completely randomized design was used. For each pathogen on each fruit type, the disease lesion diameter obtained 7 days after the treatment was measured then the mean lesion diameter of each treatment was calculated then used for comparison of the efficacy.

\subsubsection{Efficacy on Un-Wounded Fruits of Apple and Pear Stored in Incubator at $20^{\circ} \mathrm{C} \pm 1^{\circ} \mathrm{C}$}

To test efficacy of the most effective strain of $T$. harzianum formulated in invert emulsion against the fungal pathogens of postharvest mold infections, healthy un-wounded fruits of apple and pear were, first, infected with $B$. cinerea and $P$. expansum then treated with the formulated $T$. harzianum strain. Evaluation of the efficacy was done according to the time required for the appearance of disease symptoms (B. cinerea or P. expansum) on untreated and treated fruits with the formulated $T$. harzianum. The technique of inoculation with the fungal pathogens of mold infections on apple and pear fruits was done by spraying $200 \mu \mathrm{l}$ spray volume of conidial suspension of these fungal pathogens (concentration $1 \times 10^{6}$ conidia/ml) per healthy un-wounded fruit then the inoculated fruits were placed in rectangular plastic boxes $(20 \times 10 \times 10 \mathrm{~cm}$; long, wide and high, respectively). A transparent plastic film was used to cover each box. A small calibrated hand sprayer (1 L capacity) was used for spraying the intended spray volume on the un-wounded fruits. The control treatment is consisting of unwounded fruits sprayed with the same quantity of spray volume of sterile distilled water after infection with mold pathogens. Inoculated and control fruits were then sprayed with $200 \mu \mathrm{l}$ spray volume of formulated T. harzianum (concentration $1 \times 10^{7}$ conidia/ml each) per fruit in the same manner as indicated above. In each bioassay, four types of treatments were used per pathogen per fruit type. The treatments were: formulated $T$. harzianum in invert emulsion, unformulated $T$. harzianum, blank formulation of invert emulsion and control (untreated with $T$. harzianum). Five fruits per box representing 5 replicates per treatment type were used. A completely randomized design was used. The time needed for the appearance of typical symptoms of each disease (gray or blue mold) on fruits of each treatment was determined and then used for evaluation of the efficacy. The plastic 
boxes containing fruits used for bioassays were stored in an incubator at $20^{\circ} \mathrm{C} \pm 1^{\circ} \mathrm{C}$ until the appearance of the disease lesion on the incubated fruits.

\subsubsection{Efficacy on Un-Wounded Fruits of Apple and Pear Stored at $20^{\circ} \mathrm{C} \pm 5^{\circ} \mathrm{C}$ (Under Semi-Commercial Conditions)}

To test efficacy of the effective strain of $T$. harzianum formulated in invert emulsion against the fungal pathogens of postharvest mold infections on apple and pear fruits stored under semi-commercial conditions $\left(20^{\circ} \mathrm{C} \pm\right.$ $\left.5^{\circ} \mathrm{C}\right)$, rectangular plastic boxes $(20 \times 10 \times 10 \mathrm{~cm}$; long, wide and high, respectively) were used. A transparent plastic film was used to cover the fruits after treatment. These boxes are similar to those used for marketing of these fruits. The technique of inoculation with the fungal pathogens of mold infections on apple and pear fruits was done by spraying $1.0 \mathrm{ml}$ of conidial suspension of these fungal pathogens (concentration $1 \times 10^{6}$ conidia / $\mathrm{ml}$ ) on healthy un-wounded fruits kept in each plastic box. A small calibrated hand sprayer (1 L capacity) was used for spraying the intended spray volume per box containing 5 healthy un-wounded fruits. The control treatment is consisting of 5 healthy un-wounded fruits kept in one box and sprayed with the same spray volume of sterile distilled water $(1.0 \mathrm{ml})$. The inoculated and control fruits were then sprayed with $1.0 \mathrm{ml}$ spray volume of formulated $T$. harzianum (concentration $1 \times 10^{7}$ conidia/ml each) using the technique and equipment as indicated above. For each bioassay, two types of treatments were used per pathogen per fruit type. The treatments were: formulated T. harzianum in invert emulsion and control (untreated with T. harzianum). Five fruits per box representing 5 replicates per treatment type were used. A completely randomized design was used. The time needed for the appearance of typical symptoms of each disease (gray or blue mold) on fruits after the treatment was determined and then used for evaluation of the efficacy. The protection period represents the time extending from inoculation to appearance of the first symptoms of infection with the disease on treated fruits. During bioassays, the plastic boxes that contain fruits were stored in a store-room at $20^{\circ} \mathrm{C} \pm 5^{\circ} \mathrm{C}$ until the appearance of the disease symptoms on incubated fruits. These conditions are similar to those used for storing fruits of apple and pear during marketing of the product.

\subsection{Statistical Analyses}

For the targeted diseases of mold infections, the mean \% of disease lesion diameter on fruits treated with the formulated and unformulated T. harzianum was statistically analyzed using analysis of variance (ANOVA). Significant differences (at $P=0.05$ ) between the treatment means were determined by F-test. Also, the mean separation was performed using Duncan's Multiple Range test.

\section{Results}

\subsection{Efficacy of the Isolated Strains of T. harzianum}

As a result of the screening test, the strain of $T$. harzianum "TrichoPAL1" has shown the highest efficacy against B. cinerea (strain BCPAL) and P. expansum (strain PEPAL) in comparison with other strains of $T$. harzianum because this strain has significantly reduced (at $P=0.05$ ) the average mean of disease lesion diameter of both pathogens on wounded apple and pear fruits from $21.25 \mathrm{~mm}$ diameter (in the untreated control) to 12.31 mm diameter (Table 1). Therefore, it has been selected as the most effective strain of $T$. harzianum for being introduced into the selected formulation of invert emulsion. The formulated strain of $T$. harzianum was then used for further bioassays as biopesticide. However, no significant differences were obtained between the average means of disease lesion diameter of both pathogens on wounded apple and pear fruits for the other strains of $T$. harzianum "TrichoPAL2", "TrichoPAL3" and "TrichoPAL4" and the untreated control (Table 1), so they are not selected for further bioassays.

\subsection{Selection of Invert Emulsion Formulation as a Carrier of T, harzianum}

Among the different combinations (formulations) of invert emulsion prepared, the combination "IE \# 3" was selected as the most proper because it has shown a high stability for long time with no viscosity (Table 2), so that it has been selected as a carrier of T. harzianum "strain TrichoPAL1" then tested as biopesticide against mold infections on fresh fruits. The selected formulation (IE \# 3) has the following ingredients: i) a mixture of two oils of plant-origin (soybean oil: $28.50 \% \mathrm{w} / \mathrm{w}$ and coconut oil: $19.50 \% \mathrm{w} / \mathrm{w}$ ); ii) oil-soluble emulsifier (Tween 20: $2.0 \%$ $\mathrm{w} / \mathrm{w})$; iii) sterile distilled water $(22.5 \% \mathrm{w} / \mathrm{w})$; iv) conidial suspension of the selected strain of $T$. harzianum in 
Table 1. Disease lesions of Botrytis cinerea (strain BCPAL) and Penicillium expansum (strain PEPAL) formed on wounded apple and pear fruits (varieties: Red Delicious-Starking and Bartlett, respectively) 7 days after inoculation and treatment with four strains of Trichoderma harzianum (incubation of treated fruits was done in an incubator at $20^{\circ} \mathrm{C} \pm 1{ }^{\circ} \mathrm{C}$ ).

\begin{tabular}{cccccc}
\hline \multirow{2}{*}{$\begin{array}{c}\text { Strains of } \\
\text { T. harzianum }\end{array}$} & $\begin{array}{c}\text { Mean disease lesion diameter of B. cinerea and P. expansum (in mm) } \\
\text { observed on wounded apple and pear fruits when treated with } T \text {. harzianum }\end{array}$ \\
\cline { 2 - 6 } & $\begin{array}{c}\text { B. cinerea } \\
\text { on Apple fruit }\end{array}$ & $\begin{array}{c}\text { B. cinerea } \\
\text { on Pear fruit }\end{array}$ & $\begin{array}{c}\text { P. expansum } \\
\text { on Apple fruit }\end{array}$ & $\begin{array}{c}\text { P. expansum } \\
\text { on pear fruit }\end{array}$ & $\begin{array}{c}\text { Average mean of disease } \\
\text { lesion diameter }( \pm \text { SEM) } \\
\text { per strain of } T \text {. harzianum }\end{array}$ \\
\hline TrichoPAL1 & 14.25 & 10.50 & 11.00 & 13.50 & $12.31( \pm 0.79) \mathrm{A}$ \\
TrichoPAL2 & 20.75 & 17.50 & 20.00 & 19.25 & $19.37( \pm 0.61) \mathrm{B}$ \\
TrichoPAL3 & 19.50 & 21.25 & 21.00 & 19.00 & $20.19( \pm 0.48) \mathrm{B}$ \\
TrichoPAL4 & 20.25 & 18.50 & 19.75 & 20.50 & $19.50( \pm 0.41) \mathrm{B}$ \\
Untreated Control & 20.00 & 21.25 & 21.00 & 22.75 & $21.25( \pm 0.49) \mathrm{B}$
\end{tabular}

*Four fruits of each fruit type representing 4 replicates per pathogen treatment per strain were used. Therefore, 4 replicates were performed for each test $(20$ tests were performed for the 4 strains + control). SEM: standard error of the mean or standard deviation of the mean which is $=$ Standard Deviation of original distribution (SD)/Square root of Sample Size (n); ${ }^{* *}$ Means followed by the same letter are not significantly different at $P=0.05$ using ANOVA and Duncan's Multiple Range test.

Table 2. Combinations of invert emulsion formulation (IE) based on variable percentage of ingredients composing oil phase and water phase of the emulsion.

\begin{tabular}{|c|c|c|c|c|c|c|c|c|c|}
\hline \multirow{2}{*}{$\begin{array}{l}\text { Combination } \\
\text { number of invert } \\
\text { emulsion (IE) }\end{array}$} & \multicolumn{7}{|c|}{$\begin{array}{l}\% \text { of ingredients ( } \mathrm{w} / \mathrm{w} \text { ) of water phase and oil phase } \\
\text { composing the formulation of invert emulsion (IE) }\end{array}$} & \multirow{2}{*}{$\begin{array}{l}\text { Stability of } \\
\text { prepared } \\
\text { emulsion }\end{array}$} & \multirow{2}{*}{$\begin{array}{l}\text { Viscosity of } \\
\text { prepared } \\
\text { emulsion }\end{array}$} \\
\hline & $\begin{array}{c}\text { Soybean } \\
\text { oil }\end{array}$ & $\begin{array}{l}\text { Coconut } \\
\text { oil }\end{array}$ & $\begin{array}{l}\text { Tween } \\
20\end{array}$ & $\begin{array}{l}\text { Sterile } \\
\text { distilled } \\
\text { water }\end{array}$ & $\begin{array}{c}\text { Conidial } \\
\text { suspension } \\
\text { of } T \text {. harzianum }\end{array}$ & glycerin & Dehymuls k & & \\
\hline IE \# 1 & 29.00 & 18.00 & 3.00 & 21.00 & 24.00 & 4.75 & 0.25 & Not stable & $\begin{array}{l}\text { Relatively } \\
\text { viscous }\end{array}$ \\
\hline IE \# 2 & 28.50 & 19.00 & 2.50 & 22.00 & 23.00 & 4.50 & 0.50 & Not stable & $\begin{array}{l}\text { Relatively } \\
\text { viscous }\end{array}$ \\
\hline IE \# 3 & 28.50 & 19.50 & 2.00 & 22.50 & 22.50 & 4.25 & 0.75 & $\begin{array}{l}\text { Stable for } \\
\text { long time }\end{array}$ & Not viscous \\
\hline IE \# 4 & 28.50 & 19.00 & 2.50 & 23.00 & 22.00 & 4.00 & 1.00 & Not stable & viscous \\
\hline IE \# 5 & 29.00 & 18.00 & 3.00 & 23.00 & 22.00 & 4.00 & 1.00 & Not stable & Viscous \\
\hline
\end{tabular}

water (TrichoPAL1: 22.5\% w/w), v) glycerine (4.25\% w/w), and water-soluble emulsifier (Dehymuls k: 0.75\% $\mathrm{w} / \mathrm{w}$ ) (Table 2). The total \% of these ingredients (w/w) is 100 which is equally divided between the water phase and the oil phase (50\% w/w each).

\subsection{Testing the Efficacy of Formulated T. harzianum in Invert Emulsion against Mold Infections on Fresh Fruits}

\subsubsection{On Wounded Fruits of Apple and Pear Stored in an Incubator at $20^{\circ} \mathrm{C} \pm 1^{\circ} \mathrm{C}$}

The mean of disease lesion diameter of $B$. cinerea and P. expansum on wounded apple fruits has significantly decreased (at $P=0.05$ ) when treated with the formulated strain "TrichoPAL1" of $T$. harzianum in invert emulsion (combination IE \# 3). This decrease was ranged from 35.75 and $18.75 \mathrm{~mm}$ to 6.25 and $3.75 \mathrm{~mm}$ for B. cinerea and $P$. expansum, respectively, in comparison with the control (Table 3). The same trend was obtained in the results on wounded pear fruits (significant reduction in the mean of disease lesion diameter of both pathogens due to treatment with the formulated $T$. harzianum) (Table 3). However, no significant differences are present between means of the disease lesion diameter of both diseases on both types of fruits regarding the two types of control treatments (untreated fruit control and Blank formulation of invert emulsion) (Table 3. This may indicate that no harmful effects may be caused by the ingredients of the selected formulation. 
Table 3. Disease lesions of Botrytis cinerea (strain BCPAL) and Penicillium expansum (strain PEPAL) formed on wounded apple and pear fruits (variety: Red Delicious-Starking and Bartlett, respectively) after inoculation and treatment with unformulated and formulated Trichoderma harzianum (strain TrichoPAL1) in invert emulsion (incubation of the treated and control fruits was done in incubator at $\left.20^{\circ} \mathrm{C} \pm 1^{\circ} \mathrm{C}\right)$.

\begin{tabular}{|c|c|c|c|c|}
\hline \multirow{2}{*}{$\begin{array}{l}\text { Treatments with } \\
\text { T. harzianum } \\
\text { and control }\end{array}$} & \multicolumn{2}{|c|}{$\begin{array}{l}\text { Mean lesion diameter (in mm) }( \pm \text { SEM) of B. cinerea } \\
\text { appeared after } 5 \text { days of inoculation and treatment }\end{array}$} & \multicolumn{2}{|c|}{$\begin{array}{l}\text { Mean lesion diameter (in mm) }( \pm \text { SEM) of } P \text {. expansum } \\
\text { appeared after } 7 \text { days of inoculation and treatment }\end{array}$} \\
\hline & on wounded apple fruit & on wounded pear fruit & on wounded apple fruit & on wounded pear fruit \\
\hline $\begin{array}{l}\text { Formulated } \\
\text { TrichoPAL1 of } \\
\text { T. harzianum }\end{array}$ & $6.25( \pm 0.42) \mathrm{A}^{* *}$ & $7.50( \pm 0.53) \mathrm{A}^{* *}$ & $3.75( \pm 0.45) \mathrm{A}^{* *}$ & $6.2( \pm 0.49) \mathrm{A}^{* *}$ \\
\hline $\begin{array}{l}\text { Un-formulated } \\
\text { TrichoPAL1 of } \\
\text { T. harzianum }\end{array}$ & $14.50( \pm 0.78) \mathrm{B}$ & $17.00( \pm 0.67) \mathrm{B}$ & $7.50( \pm 0.81) \mathrm{B}$ & $12.50( \pm 0.77) \mathrm{B}$ \\
\hline $\begin{array}{l}\text { Blank formulation of } \\
\text { invert emulsion }\end{array}$ & $31.25( \pm 0.69) \mathrm{C}$ & $34.00( \pm 0.75) \mathrm{C}$ & $16.25( \pm 0.85) \mathrm{C}$ & $18.75( \pm 0.67) \mathrm{C}$ \\
\hline $\begin{array}{c}\text { Control } \\
\text { (untreated fruits) }\end{array}$ & $35.75( \pm(0.82) \mathrm{C}$ & $38.75( \pm 0.93) \mathrm{C}$ & $18.75( \pm 0.91) \mathrm{C}$ & $21.25( \pm 0.99) \mathrm{C}$ \\
\hline
\end{tabular}

*Four fruits of each fruit type representing 4 replicates per pathogen treatment per strain were used. Therefore, 4 replicates were performed for each test (16 tests were performed for formulated strain, unformulated strain, blank formulation and control). SEM: standard error of the mean or standard deviation of the mean which is = Standard Deviation of original distribution (SD)/Square root of Sample Size (n); ${ }^{* *}$ Within each column, means followed by the same letter are not significantly different at $P=0.05$ using ANOVA and Duncan's Multiple Range test.

\subsubsection{On Un-Wounded Fruits of Apple and Pear Stored in an Incubator at $20^{\circ} \mathrm{C} \pm 1^{\circ} \mathrm{C}$}

The time required for the appearance of the first symptoms of infection with $B$. cinerea and $P$. expansum on unwounded fresh apples stored in an incubator under controlled conditions $\left(20^{\circ} \mathrm{C} \pm 1^{\circ} \mathrm{C}\right)$ was the longest on apple fruits treated with the formulated $T$. harzianum (72 and 58 days for the two diseases, respectively) and the shortest on apple fruits of the control treatment (12 and 18 days for the two diseases, respectively) (Table 4). Intermediate time periods were required for the appearance of the first symptoms of infection with the above-mentioned diseases on apples treated with the unformulated $T$. harzianum or with the blank formulation (Table 4). These time periods represent the protection period on apple fruits needed to prevent infection with these diseases when treated with the formulated T. harzianum compared with the control. Lower values of protection periods against the same mold infections $(B$. cinerea and $P$. expansum) on un-wounded fresh pear fruits stored at $20^{\circ} \mathrm{C} \pm 1{ }^{\circ} \mathrm{C}$ were obtained when treated with the formulated $T$. harzianum compared to the control (65 and 50 days versus 11and 19 days for the two diseases, respectively) (Table 4).

\subsubsection{On Un-Wounded Fruits of Apple and Pear Stored in Semi-Commercial Conditions at $20^{\circ} \mathrm{C} \pm 5^{\circ} \mathrm{C}$}

The time required for the appearance of the first symptoms of infection with B. cinerea and $P$. expansum on un-wounded fresh fruits of apple stored in semi-commercial conditions $\left(20^{\circ} \mathrm{C} \pm 5^{\circ} \mathrm{C}\right)$ was the longest on apple fruits treated with the formulated T. harzianum (61 and 44 days for the two diseases, respectively) and the shortest on apple fruits of the control treatment (10 and 15 days for the two diseases, respectively) (Table 5). These time periods represent the protection period on apple fruits needed to prevent infection with the diseases when treated with the formulated $T$. harzianum compared with the control. Lower values of protection periods against the same mold infections (B. cinerea and $P$. expansum) on un-wounded fresh pear fruits stored at $20^{\circ} \mathrm{C} \pm$ $5^{\circ} \mathrm{C}$ were obtained when treated with the formulated T. harzianum compared to the control (50 and 40 days versus 9 and 12 day for the two diseases, respectively) (Table 5).

\section{Discussion}

Results obtained in the present research demonstrate the ability of the produced biopesticide to reduce significantly the mold infections on fresh fruits of apple and pear stored under controlled and partially controlled conditions. This ability is attributed to the capacity of the formulated strain of T. harzianum (TrichoPAL1) to suppress the growth of pathogens causing mold infections on treated fruits (B. cinerea and P. expansum) hence control these postharvest diseases. In addition to this ability, the formulation of invert emulsion (water-in-oil type) used for production of this biopesticide has significantly increased its efficacy against the targeted post 
Table 4. Time period needed for the first appearance of disease lesion of Botrytis cinerea (strain BCPAL) and Penicillium expansum (strain PEPAL) on un-wounded apple and pear fruits (variety: Red Delicious-Starking and Bartlett, respectively) treated with unformulated and formulated Trichoderma harzianum (strain TrichoPAL1) (incubation of the treated and control fruits was done in incubator at $20^{\circ} \mathrm{C} \pm 1{ }^{\circ} \mathrm{C}$ ).

\begin{tabular}{|c|c|c|c|c|}
\hline \multirow{2}{*}{$\begin{array}{l}\text { Treatments with } \\
\text { T. harzianum and control }\end{array}$} & \multicolumn{2}{|c|}{$\begin{array}{l}\text { Time needed for the first appearance } \\
\text { of lesions of } B \text {. cinerea (in days) }\end{array}$} & \multicolumn{2}{|c|}{$\begin{array}{l}\text { Time needed for the first appearance } \\
\text { of lesions of P. expansum (in days) }\end{array}$} \\
\hline & $\begin{array}{l}\text { on un-wounded } \\
\text { apple fruit }\end{array}$ & $\begin{array}{l}\text { on un-wounded } \\
\text { pear fruit }\end{array}$ & $\begin{array}{l}\text { on un-wounded } \\
\text { apple fruit }\end{array}$ & $\begin{array}{l}\text { on un-wounded } \\
\text { pear fruit }\end{array}$ \\
\hline $\begin{array}{c}\text { Formulated TrichoPAL1 } \\
\text { of } T . \text { harzianum }\end{array}$ & 72 & 65 & 58 & 50 \\
\hline $\begin{array}{l}\text { Un-formulated TrichoPAL1 } \\
\text { of T. harzianum }\end{array}$ & 39 & 40 & 32 & 38 \\
\hline $\begin{array}{l}\text { Blank formulation } \\
\text { of invert emulsion }\end{array}$ & 14 & 12 & 17 & 16 \\
\hline Control (untreated fruits) & 12 & 11 & 18 & 19 \\
\hline
\end{tabular}

*Four fruits of each fruit type representing 4 replicates per pathogen treatment per strain were used. Therefore, 4 replicates were performed for each test (16 tests were performed for formulated strain, unformulated strain, blank formulation and control).

Table 5. Time period needed for the appearance of the first disease lesion of Botrytis cinerea (strain BCPAL) and Penicillium expansum (strain PEPAL) on un-wounded apple and pear fruits (variety: Red Delicious-Starking and Bartlett, respectively) treated with formulated Trichoderma harzianum (strain TrichoPAL1) (incubation of the treated and control fruits was done in semi-commercial conditions $\left.\left(20^{\circ} \mathrm{C} \pm 5^{\circ} \mathrm{C}\right)\right)$.

\begin{tabular}{ccccc}
\hline $\begin{array}{c}\text { Treatments with } \\
\text { T. harzianum and control }\end{array}$ & $\begin{array}{c}\text { Time needed for the first appearance } \\
\text { of lesions of } B \text {. cinerea (in days) }\end{array}$ & \multicolumn{2}{c}{$\begin{array}{c}\text { Time needed for the first appearance } \\
\text { of lesions of } P \text {. expansum (in days) }\end{array}$} \\
\cline { 2 - 5 } on un-wounded & $\begin{array}{c}\text { on un-wounded } \\
\text { apple fruit }\end{array}$ & $\begin{array}{c}\text { on un-wounded } \\
\text { apple fruit }\end{array}$ & $\begin{array}{c}\text { on un-wounded } \\
\text { pear fruit }\end{array}$ \\
\hline $\begin{array}{c}\text { Formulated TrichoPAL1 } \\
\text { of } T \text {. harzianum } \\
\text { Control (untreated fruits) }\end{array}$ & 61 & 50 & 44 & 40 \\
\hline
\end{tabular}

*Four fruits of each fruit type representing 4 replicates per pathogen treatment per strain were used. Therefore, 4 replicates were performed for each test (8 tests were performed for formulated strain and control).

harvest mold infections when compared with the unformulated form of the strain. The reason for increasing this efficacy is explained by selection of certain ingredients for being introduced into the formulation. For example, a mixture of two oils of plant-origin: soybean oil $(28.50 \% \mathrm{w} / \mathrm{w})$ and coconut oil $(19.50 \% \mathrm{w} / \mathrm{w})$ characterized by having a high content of monounsaturated fat suitable for preparing a stable invert emulsion is used. In addition to using two types of emulsifiers: oil-soluble emulsifier (Tween 20: $2.0 \% \mathrm{w} / \mathrm{w}$ ) and water-soluble emulsifier (Dehymuls k: $0.75 \% \mathrm{w} / \mathrm{w})$ for producing a homogenous and stable invert emulsion. Glycerine $(4.25 \% \mathrm{w} / \mathrm{w})$ was also used for decreasing the activity of water molecule in the emulsion by preventing its active evaporation. A similar enhancement of the efficacy has been reported for other strains of $T$. harzianum when introduced into invert emulsion. For example, T. harzianum strain CI306 formulated in invert emulsion (water-in oil type) and applied against other types of infections on fruits and other plant parts [15]-[17]. It is also important to mention that the ingredients of our formulation of invert emulsion used in biopesticide have no environmental side-effects or harmful toxic effects on treated fruits since they are mainly composed of natural substances that are used as food additives or for manufacturing of cosmetics. Moreover, the fungus strains of $T$. harzianum used in biopesticide are easy to isolate from nature as a soil borne fungus and easy to cultivate on culture medium, in addition to that they are cheap to maintain and easy to apply.

It is well-known that the various strains of $T$. harzianum can establish a mycoparasitic relationship with their host pathogens during parasitism. This relationship could be done by interfering with the development and growth of pathogens after conidial germination through coiling of their mycelium over the pathogen mycelium or by disrupting the host fungus cell wall and consequent death of the pathogen [18] [19]. Antibiosis is another antagonistic relationship made by certain strains of $T$. harzianum. This antibiosis could be done by producing antifungal antibiotics in form of extracellular products (for example, hydrolytic enzymes like chitinases, glucanases 
and proteases) [18] [20]-[24]. Also, these strains could be propagated after successful host infection and distribution within the contaminated environment (horizontal transmission is most probable). The above characteristics make these antagonistic fungi excellent candidates as biocontrol agents in the integrated management strategies of many plant diseases including postharvest diseases [21] [25].

From a practical point of view, formulation of $T$. harzianum strains is very necessary for protecting the introduced fungus and enhancing its efficacy. Until present, many researchers have attempted to formulate strains and isolates of T. harzianum using appropriate formulations. For example, formulation of T39 isolate of T. harzianum in a powder form (commercially sold as Trichode ${ }^{\mathrm{TR}}$ ) then application of it against pathogens of many foliar diseases such as Botrytis cinerea, Pseudoperonospora cubensis, Sclerotinia sclerotiorum and Sphaerotheca fusca (syn. S. fuliginea) in cucumber under commercial greenhouse conditions [26]. Also, formulation of the strain 1295-22 (T-22) of T. harzianum in a liquid form (commercialized as T-22 Planter Box ${ }^{\mathrm{TM}}$ ) containing the conidial suspension of the fungus used for the seed treatment against damping-off diseases [7] [27]. The same strain was also formulated in a liquid form but this form contains the entire thallus of the fungus colonized on clay particles (commercialized as RootShield ${ }^{\mathrm{TM}}$ ) for control of soil borne diseases [7] [27]. There is also another T. harzianum product available in the Czech Republic and Denmark for the greenhouse use called commercially (Supresvit ${ }^{\mathrm{TM}}$ ) in a dispersible powder containing conidia of the strain PV5736-89 and used for soil or potting mixes to control damping-off and root rots of ornamentals and forest tree-seedlings [7]. In comparison with the above formulations of $T$. harzianum, our formulation of invert emulsion (water-in-oil type) contains the suspended conidia of the fungus strain "TrichoPAL1" in the emulsion. These conidia were incorporated in the emulsion during its preparation so that the viability of these conidia could be preserved for long time realizing a significant reduction in the mean of disease lesion diameter of pathogens challenged. In a previous research, one of the prepared formulations of invert emulsion (water-in-oil type) that contained the conidia of an effective strain of the fungus "CI306" did not significantly lose its viability after 6 weeks of their introduction into emulsion. Also, it achieved a high biological efficacy against $B$. cinerea on strawberry by decreasing the disease lesion diameter of the pathogen by $44.0 \%$ to $55.0 \%$ compared to the control [15]. This proves again the benefits of our formulation and its efficacy compared to other formulations.

\section{Conclusion}

An effective strain of $T$. harzianum was successfully formulated as biopesticide using a stable and non-viscous formulation of invert emulsion (water-in-oil type) then tested against target pathogens of postharvest mold infections on fruits of apple and pear. Treatments with the tested biopesticide have reduced significantly the mean of disease lesion diameter on previously infected fruits before treatment. Also, they have protected fruits for a long time from later infections (protection period up to 2.5 months). Due to above demonstration of biopesticide effectiveness, it is recommended to test it at a large scale for the control of mold infections on marketed fruits stored under variable conditions.

\section{Acknowledgements}

I would like to thank the "Union of Arab Universities for Supporting the Palestinian Universities" for its financial support of the present research project. My special thanks for the deanship of the scientific research of An-Najah National University for their help in accomplishment of this research project.

\section{References}

[1] Eckert, J.W. and Ogawa, J.M. (1985) The Chemical Control of Postharvest Diseases: Subtropical and Tropical Fruits. Annual Review of Phytopathology, 23, 421-454. http://dx.doi.org/10.1146/annurev.py.23.090185.002225

[2] Eckert, J.W. and Ogawa, J.M. (1988) The Chemical Control of Postharvest Diseases: Deciduous Fruits, Berries, Vegetables and Root/Tuber Crops. Annual Review of Phytopathology, 26, 433-469. http://dx.doi.org/10.1146/annurev.py.26.090188.002245

[3] El-Ghaouth, A., Arul, J. and Asselin A. (1992) Antifungal Activity of Chitosan on Two Postharvest Pathogens of Strawberry Fruit. Phytopathology, 82, 398-402. http://dx.doi.org/10.1094/Phyto-82-398

[4] Tripathi, P. and Dubey, N.K. (2004) Exploitation of Natural Products as an Alternative Strategy to Control Postharvest Fungal Rotting of Fruit and Vegetables. Postharvest Biology and Technology, 32, 235-245.

http://dx.doi.org/10.1016/j.postharvbio.2003.11.005 
[5] Janisiewicz, J.W. and Korsten, L. (2002) Biological Control of Postharvest Diseases of Fruits. Annual Review of Phytopathology, 40, 411-441. http://dx.doi.org/10.1146/annurev.phyto.40.120401.130158

[6] Spadaro, D. and Gullino, M.L. (2003) State of the Art and Future Prospects of the Biological Control of Postharvest Fruit Diseases. International Journal of Food Microbiology, 91, 185-194. http://dx.doi.org/10.1016/S0168-1605(03)00380-5

[7] Butt, T.M., Jackson, C.W. and Magan, N. (2001) Fungi as Biocontrol Agents: Progress, Problems and Potential. CABI Publishing, UK, 384. http://dx.doi.org/10.1079/9780851993560.0000

[8] Sharma, D.R., Singh, D. and Singh, R. (2009) Biological Control of Postharvest Diseases of Fruits and Vegetables by Microbial Antagonists: A Review. Biological Control, 50, 205-221. http://dx.doi.org/10.1016/j.biocontrol.2009.05.001

[9] Wisniewski, M.E. and Wilson, C.L. (1992) Biological Control of Postharvest Diseases of Fruits and Vegetables: Recent Advances. HortScience, 27, 94-98.

[10] Bora, L. C., Minku, D., Das, B. C. and Das, M. (2000) Influence of Microbial Antagonists and Soil Amendments on Wilt Severity and Yield of Tomato. Indian Journal of Agricultural Sciences, 70, 390-392.

[11] Borras, D. and Aguilar, R.V. (1990) Biological Control of Penicillium digitatum on Postharvest Citrus Fruit. International Journal of Food Microbiology, 11, 179-184. http://dx.doi.org/10.1016/0168-1605(90)90053-8

[12] Chalutz, E., Droby, S. and Wilson, C.L. (1988) Microbial Protection against Postharvest Diseases of Citrus Fruit. Phytoparasitica, 16, 195-196.

[13] Elad, Y. (1994) Biological Control of Grape Gray Mold by Trichoderma harzianum. Crop Protection, 13, 35-38. http://dx.doi.org/10.1016/0261-2194(94)90133-3

[14] Connick Jr., W.J., Daigle, D.J. and Quimby Jr., P.C. (1991) An Improved Invert Emulsion with High Water Retention for Mycoherbicide Delivery. Weed Technology, 5, 442-444.

[15] Batta, Y. (1999) Biological Effect of Two Strains of Microorganisms Antagonistic to Botrytis cinerea: Causal Organism of Gray Mold on Strawberry. An-Najah University Journal for Research A: Natural Sciences, 13, 67-83.

[16] Batta, Y. (2001) Effect of Fungicides and Antagonistic Microorganisms on Black Fruit Spot Disease on Persimmon. Dirasat: Agricultural Sciences, 28, 165-171.

[17] Batta, Y. (2005) Control of Alternaria Spot Disease on Loquat Using Detached Fruits and Leaf-Disk Assay. An-Najah University Journal of Research A: Natural Sciences, 19, 69-81.

[18] Goldman, M.H. and Goldman, G.H. (1998) Trichderma harzianum Transformant Has High Extracellular Alkaline Proteinase Expression during Specific Mycoparasitic Interaction. Genetics of Molecular Biology, 21, 15-18. http://dx.doi.org/10.1590/S1415-47571998000300007

[19] Monte, E. (2001) Understanding Trichoderma: Between Biotechnology and Microbial Ecology. International Journal of Microbiology, 4, 1-4.

[20] Benitez, T., Rincon, A.M., Limon, M.C. and Codon, N.C. (2004) Biocontrol Mechanisms of Trichderma Strains. International Microbiology, 7, 247-260

[21] Elad, Y. (2000) Biological Control of Foliar Pathogens by Means of Trichoderma harzianum and Potential Modes of Action. Crop Protection, 19, 709-714. http://dx.doi.org/10.1016/S0261-2194(00)00094-6

[22] Ghisalberti, E.L. and Sivasithamparam, K. (1991) Review of Antifungal Antibiotics Produced by Trichoderma spp. Soil Biology and Biochemistry, 23, 10011-1023. http://dx.doi.org/10.1016/0038-0717(91)90036-J

[23] Grondona, I., Hernosa, R., Tejada, M., Gomis, M.D., Mateos, P.F., Bridge, P.D., Monte, E. and Garcia-Acha, I. (1997) Physiological and Biochemical Characterization of Trichoderma harzianum, a Biological Control Agent against Soil Borne Fungal Plant Pathogens. Applied and Environmental Microbiology, 63, 3189-3198.

[24] Schirmbock, M., Lorito, M., Wang, Y.L., Hayes, C.K., Arisan-Atac, I., Scala, F., et al. (1994) Parallel Formation and Synergism of Hydrolytic Enzymes and Peptaibol Antibiotics, Molecular Mechanisms Involved in the Antagonistic Action of Trichoderma harzianum against Phytopathogenic Fungi. Applied and Environmental Microbiology, 60, 43644370.

[25] Droby, S., Wsiniewski, M., El-Ghaouth, A. and Wilson, C. (2003) Biological Control of Postharvest Diseases of Fruit and Vegetables: Current Achievements and Future Challenges. Acta Horticulturae, 628, 703-713. http://dx.doi.org/10.17660/ActaHortic.2003.628.89

[26] Elad, Y. (2000) Trichoderma harzianum T39 Preparation for Biocontrol of Plant Diseases Control of Botrytis cinerea, Sclerotinia sclerotiorum and Cladosporium fulvum. Biocontrol Science and Technology, 10, 499-507. http://dx.doi.org/10.1080/09583150050115089

[27] Jin, X., Hayes, C.K. and Harman, G.E. (1992) Principles in the Development of Biological Control Systems Employing Trichoderma Species against Soil-Borne Plant Pathogenic Fungi. In: Leatham, G.F., Ed., Frontiers in Industrial Mycology, Mycological Society of America, Brock/Springer Series in Contemporary Bioscience, Springer, New York, 174-195. http://dx.doi.org/10.1007/978-1-4684-7112-0 12 